\title{
A 12-year-old girl presenting with recurrent abdominal pain and vomiting
}

\author{
Kaniz Fathema, Ferdous Ara Begum, Salahuddin Al-Azad and Khan Lamia Nahid
}

\section{Article Info \\ Department of Pediatric Gastroenterol- ogy and Nutrition, Bangabandhu Sheikh Mujib Medical University, Dhaka, Bang- ladesh (KF, FAB); Department of Radiol- ogy and Imaging, Bangabandhu Sheikh Mujib Medical University, Dhaka, Bang- ladesh (SAA); Department of Pediatric Gastroenterology and Nutrition, Banga- bandhu Sheikh Mujib Medical Universi- ty, Dhaka, Bangladesh (KLN) \\ For Correspondence: \\ Kaniz Fathema \\ kanizkmc21@gmail.com \\ Received: \\ Accepted: \\ Available Online: \\ 12 February 2021 4 April 2021 \\ ISSN: 2224-7750 (Online) 2074-2908 (Print) \\ DOI: $10.3329 /$ bsmmuj.v14i2.52722}

\section{Cite this article:}

Fathema K, Begum FA, Al-Azad S, Khan Nahid KL. A 12-year-old girl presenting with recurrent abdominal pain and vomiting. Bangabandhu Sheikh Mujib Med Univ J. 2021; 14: 21-26.

\section{Copyright:}

The copyright of this article is retained by the author(s) [Atribution CC-By 4.0]

Available at:

www.banglajol.info

A Journal of Bangabandhu Sheikh Mujib Medical University, Dhaka, Bangladesh

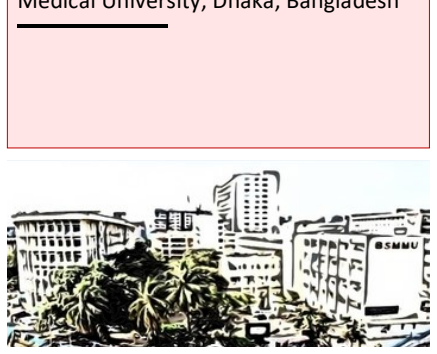

\section{Presentation of Case}

Dr. Kaniz Fathema (Resident): A 12-year-old immunized girl with only issue of non-consanguineous parents presented with the complaints of severe, agonizing, and continued upper abdominal pain which radiated to the back, aggravated after taking food and partially relieved on leaning forward for the last 4 days. The pain was associated with several episodes of vomiting. She had a history of similar types of 3 attacks within the last 1 year and in between attacks, she was comparatively well. On query, the mother gave a history of gradual weight loss. There was no history of fever, abdominal trauma, any surgery, jaundice, nocturnal exacerbation of abdominal pain, constipation, excessive drinking of water, increased frequency of micturition, the passage of oily greasy stool, family history of the same type of illness, or taking any offending drugs.

On examination, she was ill-looking, non-anemic, anicteric, and vitally stable. The capillary blood glucose level was $14.5 \mathrm{mmol} / \mathrm{L}$. Anthropometrically the patient was severely underweight and severely wasted. The per abdominal examination revealed tenderness present in the epigastric region with no organomegaly. The bowel sound was present. Routine laboratory investigation showed hemoglobin level $11 \mathrm{~g} / \mathrm{dL}$, total count of WBC $10,500 / \mathrm{mm}^{3}$, plasma fasting glucose level $7.5 \mathrm{mmol} / \mathrm{L}$. Two hours after $75 \mathrm{~g}$ glucose intake, it was 11.9 $\mathrm{mmol} / \mathrm{L}$. The serum electrolytes were within normal range. The prothrombin time was 13 sec. The international normalization ratio was 1.1. The serum triglyceride level was $72 \mathrm{mg} / \mathrm{dL}$. Other data were, serum calcium: $9.5 \mathrm{mg} / \mathrm{dL}$; serum creatinine: $0.6 \mathrm{mg} / \mathrm{dL}$; fecal fat: $10-12$ drops/HPF (negative). The serum amylase level was $481 \mathrm{u} / \mathrm{L}$ (range: 25-115 u/L) and serum lipase level was $1377 \mathrm{u} / \mathrm{L}$ (range: 8-78 u/ L) (both were more than 3 times upper limit of normal).

The ultrasonography of the whole abdomen showed the pancreas was shrunken in size with heterogeneous echotexture. The main pancreatic duct was dilated, and suggestive of chronic pancreatitis. There was no other abnormal finding other than pancreas.

\begin{abstract}
Provisional Diagnosis
Chronic pancreatitis with diabetes mellitus with failure to thrive

\section{Differential Diagnosis}

Dr. Nazmul Hassan (Resident): As the patient presented with characteristic abdominal pain of pancreatitis and also had the previous history of a similar type of 3 attacks within 1 year, in between attacks, patient was symptom-free. On Investigation patient's serum lipase was more than three times of upper limit of normal. So from these, it could be a case of acute recurrent pancreatitis.
\end{abstract}

\section{Acute recurrent pancreatitis}

Dr. Nazmul Hassan (Resident): The term acute recurrent pancreatitis was first reported in the Marseille classification of pancreatitis 1 and According to INSPIRE criteria is defined as at least two episodes of acute pancreatitis separated by at least 1-month pain-free interval or complete normalization of serum pancreatic enzyme levels and pain-free period, irrespective of a specific time interval between acute pancreatitis episodes.? The incidence of Acute recurrent pancreatitis in children is about $10 \%$ after the first episode of acute pancreatitis. 3 Several etiologic factors play a role in acute recurrent pancreatitis; in fact, any cause of acute pancreatitis can lead to recurrent episodes if it is not corrected. The etiology of acute recurrent pancreatitis can be mechanical, inherited, autoimmune, metabolic, and druginduced, parasites, vascular disorders, and toxic substances may also induce episodes of acute pancreatitis. However, despite today's diagnostic technology, idiopathic acute recurrent pancreatitis is about $25-30 \%$ of cases. 1 The acute recurrent pancreatitis child commonly presented with abdominal pain associated with vomiting and less commonly abdominal tenderness, abdominal distention, fever, tachycardia, hypotension, jaundice, and back pain. $\underline{4}$ The diagnosis of acute recurrent pancreatitis is confirmed by the establishment of the evidence of acute pancreatitis by laboratory and imaging findings along with a 
Table I

\begin{tabular}{|c|c|c|}
\hline \multicolumn{3}{|c|}{ Laboratory investigations of patient } \\
\hline Parameter & Patient & References \\
\hline Hemoglobin $(\mathrm{g} / \mathrm{dL})$ & 11 & $13.5 \pm 1.3$ \\
\hline Total count of white blood cell $\left(\times 10^{9} / \mathrm{L}\right)$ & 10.5 & $7.0 \pm 3$ \\
\hline \multicolumn{3}{|l|}{ Differentials } \\
\hline Neutrophil & 75 & $40-80 \%$ \\
\hline Lymphocyte & 20 & $20-40 \%$ \\
\hline Eosinophil & 2 & $1-6 \%$ \\
\hline Monocyte & 3 & $2-10 \%$ \\
\hline Platelet count (x109 /L) & 400 & $150-400$ \\
\hline ESR ( $\mathrm{mm}$ in 1st hour) & 15 & $0-10$ \\
\hline Prothrombin time (sec) & 13 & $12-16$ \\
\hline International normalized ratio & 1.1 & $<1.4$ \\
\hline Fasting blood sugar (mmol/L) & 7.5 & $3.5-6.0$ \\
\hline Serum triglyceride $(\mathrm{mg} / \mathrm{dL})$ & 72 & $<150$ \\
\hline Serum amylase (U/L) & 481 & $25-115$ \\
\hline Serum lipase (U/L) & 1377 & Up to 60 \\
\hline \multicolumn{3}{|l|}{ Serum electrolyte: $(\mathrm{mmol} / \mathrm{L})$} \\
\hline Sodium $\left(\mathrm{Na}^{+}\right)$ & 137 & $136-148$ \\
\hline Potassium $\left(\mathrm{K}^{+}\right)$ & 4.4 & $3.5-5.2$ \\
\hline Chloride ( $\left.\mathrm{Cl}^{-}\right)$ & 98 & $98-108$ \\
\hline Carbon dioxide $\left(\mathrm{CO}_{2}\right)$ & 24 & $21-32$ \\
\hline Serum alanine aminotransferase (U/L) & 19 & $30-65$ \\
\hline Serum calcium (mg/dL) & 9.5 & $8.1-10.4$ \\
\hline Serum creatinine $(\mathrm{mg} / \mathrm{dL})$ & 0.6 & $0.9-1.3$ \\
\hline Fecal fat & 10-12 drops/HPF & Negative \\
\hline
\end{tabular}

history of recurrence.

\section{Acute pancreatitis}

Dr. Ferdous Ara Begum (Resident): Acute pancreatitis is a reversible process characterized by the histological evidence of inflammation of pancreatic parenchyma, interstitial edema, and infiltration of inflammatory cells with variable degrees of cellular apoptosis, necrosis, and hemorrhage. 5 Acute pancreatitis is diagnosed by the presence of at least two of the following three criteria: $:-9$ a) characteristic abdominal pain of acute onset, severe dull ache, especially in the epigastric region may radiate to back, aggravated by eating or drinking, usually after taking fatty food and relieved by leaning forward or knee-chest position; $\underline{10}$ b) serum amylase and /or lipase level at least more than 3 times of upper normal limit; c) positive imaging findings of acute pancreatitis.
There are several etiologies of acute pancreatitis. Among the metabolic causes hypertriglyceridemia is one of the established cause of pancreatitis. 11

\section{Chronic pancreatitis}

Dr. Md. Benzamin (Resident): Chronic pancreatitis is defined by any one of the following: a) abdominal pain consistent with pancreatic origin and imaging findings suggestive of chronic pancreatic damage, b) evidence of exocrine pancreatic insufficiency and imaging findings suggestive of pancreatic damage, or c) evidence of endocrine pancreatic insufficiency and imaging findings suggestive of pancreatic damage, or d) a surgical or pancreatic biopsy demonstrating histopathology compatible with chronic pancreatitis. 12 The pathophysiology of chronic pancreatitis is remaining unclear and idiopathic causes most likely comprise a large percentage of pediatric patients with chronic pancreatitis. $\underline{13}$ In general, the TIGAR-O (toxic-metabolic, idiopathic, genetic, autoimmune, recurrent, and severe acute pancreatitis, obstructive) are the most likely causes of chronic pancreatitis in children. $\underline{13}$ Chronic pancreatitis child is mainly presented with mild to moderate upper abdominal pain, weight loss, diarrhea, steatorrhoea, recurrent acute pancreatitis, and rarely jaundice and upper gastrointestinal bleeding. $\underline{4}$ The diagnostic modalities of chronic pancreatitis are laboratory tests (serum amylase, lipase, calcium, lipid panel, total and direct bilirubin, alkaline phosphatase, GGT, AST, ALT, fasting serum glucose), fecal elastase-1, 72 hours fecal fat, sweat $\mathrm{Cl} / \mathrm{NPD}$, imaging studies (ultrasonography, computer tomography, MRCP, EUS, ERCP), genetic testing (PRSS1, CFTR, SPINK1, CTRC). $\underline{14}$

Dr. Ferdous Ara Begum (Resident): Although our patients presenting features, physical examination, history of recurrent attacks of abdominal pain, and in between attack she was relatively well are suggestive of acute recurrent pancreatitis but ultrasonography reveals pancreas was shrunken in size with heterogeneous echotexture. So, acute recurrent pancreatitis was excluded.

Dr. Fathema (Resident): As a patient having typical abdominal pain for pancreatitis, clinical malnutrition, young age at onset, and presence of diabetes with the absence of ketosis (though this patient has no chronic abdominal pain since childhood), so we had a suspicion about fibrocalculous pancreatic diabetes. Then, we went for an X-ray. The classic plain radiographic feature of fibrocalculous pancreatic diabetes is the presence of coarse, well-defined, and dense pancreatic calcifications. The calculi are mostly situated to the right of the first or second lumbar vertebrae, but may rarely overlap the spine. But we found a normal x-ray abdomen. So, we went for MRCP.

Dr. Salahuddin Al-Azad (Professor): MRCP's finding 


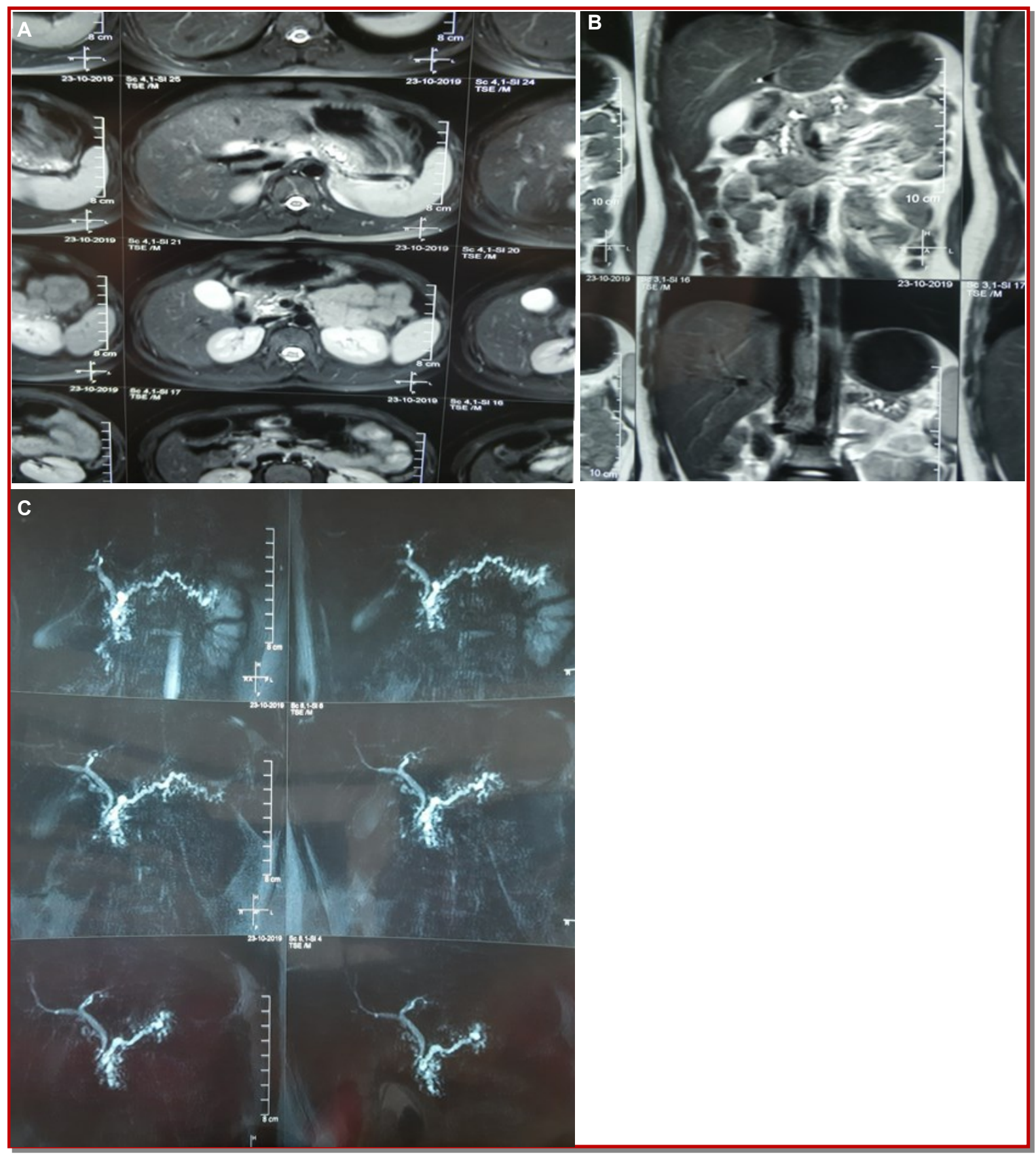

Figure 1: MRCP a) Main pancreatic duct was dilated, irregular in outline, and beaded appearance with dilatation of its branches; $b$ ) Multiple filling defects were noted in the lumen of main pancreatic duct; c) Pancreas was reduced in volume with irregular outline having multiple filling defects in the parenchyma that was suggestive of chronic calcified pancreatitis with dilated main pancreatic duct with duct lithiasis

of tropical calcific pancreatitis was the enlargement of the pancreas, calcifications in parenchyma, and post-inflammatory fluid collections adjacent to the gland, ductal dilatation. In this case, it showed pancreas was reduced in volume with irregular outline, the main pancreatic duct was dilated, irregular in outline, and beaded appearance with dilatation of its branches. Multiple filling defects were noted in the parenchyma and lumen of main pancreatic duct that was suggestive of chronic calcified pancreatitis.

\section{Dr. Fathema's Diagnosis}

Tropical calcific pancreatitis/fibrocalculous pancreatic diabetes

\section{Discussion}

Dr. Khan Lamia Nahid (Assistant Professor): Tropical calcific pancreatitis is a rare condition in children. $\underline{15}$ It is a juvenile form of chronic calcific, non-alcoholic 
pancreatitis, prevalent almost exclusively in the countries of the tropical world.16 Several names have been proposed for this type of chronic pancreatitis including tropical chronic pancreatitis, tropical calcific pancreatitis, juvenile pancreatitis syndrome, Afro-Asian pancreatitis, and fibrocalculous pancreatic diabetes. Fibrocalculous pancreatic diabetes was introduced by the World Health Organization (WHO) Study Group report on diabetes,, 1 to denote the latter, diabetic stage of the syndrome.16,17 Tropical pancreatitis was first described by Zuidema from Indonesia in 1959.18 The first case of pancreatic calculi from India was reported by Kini in 1937.19 Later, Geevarghese described several patients from Kerala state in southwest India, $\underline{20}$ and the disease was reported from many tropical countries in Africa and Asia.21 The term tropical, reflecting the disease's geographical distribution, became a part of the disease's name. The term tropical pancreatitis, based on geographic distribution, seems illogical. This is borne out by recent reports of tropical pancreatitis from outside the tropics including Bangladesh.21, 22 The exact etiopathogenesis remain elusive. The following have been proposed: a) Malnutrition; b) role of cassava and other dietary toxins; c) familial and genetic factors; d) oxidative stress and trace element deficiency states. $\underline{16}$ Consumption of cassava, being common in the populations afflicted by tropical pancreatitis, was also suspected to play a causative role. 11 Studies have shown that there is some evidence of permanent pancreatic damage after recovery from malnutrition. Fibrosis follows atrophy of the pancreatic acinar cells in Kwashiorkor. $\underline{23,24}$ Familial clustering of tropical pancreatitis has been reported. Familial or hereditary etiological factors or common environmental or dietary factors may play a role.21 SPINK1, CFTR mutations, or as yet unknown gene mutations that play a role in handling environmental toxins may play a role. 20

Fibrocalculous pancreatic diabetes is a rare etiology of diabetes, seen mainly in developing countries. A family-oriented study was carried out in 67 Bangladeshi families, consisting of a proband with fibrocalculous pancreatic diabetes and both parents, to specify whether an association exists between fibrocalculous pancreatic diabetes susceptibility and either the major histocompatibility complex or insulin gene (INS) loci. This study confirms an association between fibrocalculous pancreatic diabetes and the major histocompatibility complex but there was no association between fibrocalculous pancreatic diabetes and INS was found. 25

The classical triad of clinical presentation in tropical chronic pancreatitis: recurrent upper abdominal pain, maldigestion leading to steatorrhoea and diabetes (fibrocalculous pancreatic diabetes)..$\underline{16}$ Other clinical features include signs of malnutrition, nutrient deficiencies, a cyanotic hue of the lips, bilateral enlargement of parotid glands, a potbelly, and, sometimes, nutritional edema. .20

Diagnostic criteria for fibrocalculous pancreatic diabetes include: $\underline{26}$ a) Occurrence in a tropical country; b) diabetes by the WHO study group criteria; c) evidence of chronic pancreatitis (calculi on an x-ray or at least three of the following: i) abnormal pancreatic morphology by ultrasonography; ii) chronic abdominal pain since childhood; iii) steatorrhoea; iv) abnormal pancreatic function test); d) the absence of other causes of chronic pancreatitis i.e., alcoholism, hepatobiliary disease or primary hyperparathyroidism, etc.

Investigations for diagnosis include ultrasonography, plain abdominal X-ray, computed tomography, endoscopic retrograde cholangiopancreatography, endoscopic ultrasonography, tests of exocrine pancreatic function, and tests of endocrine pancreatic function. Our patient fulfilled criteria like she is from a tropical region, diabetic according to WHO criteria, abnormal morphology on ultrasonography, pancreatic function abnormality, and absence of other causes of chronic pancreatitis.

Patients with fibrocalculous pancreatic diabetes usually necessitate insulin though in small quantities, which is due to the presence of residual betacell function reflected by the intermediate C-peptide levels seen in these patients. 27 We managed our patient with the consultation of pediatric endocrinology department by diet, discipline. Our case had no macrovascular or microvascular complications of diabetes mellitus. Long-term microvascular compli-cations of fibrocalculous pancreatic diabetes are retinopathy, neuropathy, and nephropathy. $\underline{.6}$ Macro-vascular complications were less common due to the usual young age of onset, their leanness and the low cholesterol levels. $\underline{28}$

Pain is a major problem in fibrocalculous pancreatic diabetes, may need surgical interventions when severely intractable and recurrent, evidenced by this patient having relief of pain following annual ERCP and stenting. Drainage procedures, sphincteroplasty, pancreatic necrosectomy, and celiac plexus ablation are surgical options. Early surgery has been found to prevent the development of diabetes in the early stages of the disease. 29 Our patient already developed diabetes.

Recurrent intractable pain, insulin resistance, recurrent hypoglycemia, malnutrition, inability to adequately correct micro and macronutrient deficiency, poor drug compliance, misdiagnosis, and late diagnosis are challenges in management. 30 So, early diagnosis and effective treatment can significantly reduce mortality and morbidity.

\section{Dr. Bodhrun: What is tropical pancreatitis?}

Dr. Fathema: Tropical pancreatitis is a special type of chronic pancreatitis that is seen mainly in tropical 
countries. The prevalence of tropical pancreatitis is about $126 / 100,000$ population in southern India. It occurs usually in young people, involves the main pancreatic duct, and results in large ductal calculi.

Dr. Sharmistha Ghosal: What is calcific pancreatitis?

Dr. Ferdous: Chronic calcifying/calcific pancreatitis is a special form of chronic pancreatitis that tends to calcify or is associated with pancreatic lithiasis.

Dr. Dipannita Saha: What condition can mimic pancreatitis?

Dr. Ferdous: A couple of acute abdominal conditions that can mimic pancreatitis include: impacted gall stones (biliary colic), gastric perforation, or duodenal ulcer.

Dr. Maimuna Sayeed: Why there is no steatorrhoea in this patient?

Dr. Fathema: About one-third of the patient complaints of passing large bulky and oily stools while stool examination in our patient showed the normal amount of fat globules. The absence of steatorrhoea was supposed to the low fat and high carbohydrate dietary habit.

Dr. Saidul Islam: Why no ketosis in this patient?

Dr. Ferdous: Although there is a high sugar level may found in fibrocalculous pancreatic diabetes but there is absent ketosis, which may due to the residual beta-cell function, reflected by the moderate level of C-peptide.

\section{Dr. Shafiul Azam Nizam: How malnutrition occurs?}

Dr. Rafiqul Islam: Normal pancreatic function ensures effective digestion and absorption of nutrients. Chronic pancreatitis refers to a syndrome of longstanding pancreatic injury and because of its role in digestion, chronic pancreatitis is responsible.

Dr. Umme Zannat: Is there any role of gene sequencing?

Dr. Fathema: Current evidence confirms a link between the serine protease inhibitor Kazal type 1 (SPINK 1) gene, and tropical calcific pancreatitis.

\section{Final Diagnosis}

Tropical calcific pancreatitis/fibrocalculous pancreatic diabetes

\section{Follow-up}

The patient was doing well with reduced abdominal pain and follow-up after 2 weeks.

\section{Conflict of Interest}

Authors declare no conflict of interest

\section{References}

1. Testoni PA. Acute recurrent pancreatitis: Etiopathogenesis, diagnosis, and treatment. World J Gastroenterol. 2014; 20: 16891-901.

2. Grzybowska-Chlebowczyk U, Jasielska M, FlakWancerz A, Więcek S, Gruszczyńska K, Chlebowczyk W, Woś H. Acute pancreatitis in children. Przeglad Gastroenterologiczny. 2018; 13: 69.

3. David Whitcomb and Mark E. Lowe. Acute and Chronic pancreatitis. Walker's pediatric gastrointestinal disease. 6th ed. pp 4606-38.

4. Lowe ME. Acute and chronic pancreatitis. In: Pediatric practice gastroenterology. Bishop WP (ed). New York, McGraw Hill, 2010, pp 428-40.

5. Ahmed KU, Ahad MA, Alim MA, Ekram ARMS. Clinical profile of acute pancreatitis in a teaching hospital. Bangladesh Med J Khulna. 2016; 49: 7-12.

6. Musabbir N, Karim ASMB, Sultana K, Anwar SA. Acute pancreatitis in children. Northern Int Med Coll J. 2017; 8: 235-38.

7. Hasan MM, Laila SZ, Mamun MH. Clinical pattern and management of acute pancreatitis: Our experience. J Bangladesh Coll Phys Surg. 2013; 31: 122-27.

8. Musabbir N, Karim ASMB, Mazumder MW, Sultana K, Anwar SA, Haque A, Hussain F. Clinical profile of acute pancreatitis in children in a tertiary level hospital of Bangladesh. Bangladesh J Child Health. 2016; 40: 160-65.

9. 17. Abu-El-Haija M, Kumar S, Szabo F, Werlin S, Con-well D, Banks P, Morinville VD, NASPGHAN Pancreas Committee. Classification of acute pancreatitis in the pediatric population: Clinical report from the NASPGHAN pancreas committee. J Pediatr Gastroenterol Nutr. 2017; 64: 984-90.

10. Das D, Paul DP, Iqbal KS. Chronic calcific pancreatitis in a 9-year-old boy. J Enam Med Coll. 2012; 2: 43-45.

11. Nahar L, Karim AB, Rukunuzzaman M, Yasmin A. An $8 \frac{1}{2}$ year old girl presented with pain abdomen with hypertriglyceremia. Bangabandhu Sheikh Mujib Medical Univ J. 2018; 11: 161-67

12. Sobczynska-Tomaszewska A, Bak D, Oralewska B, Oracz G, Norek A, Czerska K, et al. Analysis of CFTR, SPINK1, PRSS1 and AAT mutations in children with acute or chronic pancreatitis. J Pediatr Gastroenterol Nutr. 2006; 43: 299-306.

13. Witt H, Apte MV, Keim V, Wilson JS. Chronic pancreatitis: Challenges and advances in pathogenesis, genetics, diagnosis, and therapy. Gastroen- 
terology 2007; 132: 1557-73.

14. Catalano MF, Sahai A, Levy M, Romagnuolo J, Wiersema M, Brugge W, Freeman M, Yamao K, Canto M, Hernandez LV. EUS-based criteria for the diagnosis of chronic pancreatitis: The Rosemont classification. Gastrointest Endosc. 2009; 69: 125161.

15. Lagerloef $\mathrm{HOH}$. Pancreatic functions and pancreatic disease studied by means of secretin. New York, Macmillan Press, 1942, pp 45-54.

16. Barman KK, Premalatha G, Mohan V. Tropical chronic pancreatitis. Postgrad Med J. 2003; 79: 60615.

17. WHO Study Group. Report on diabetes mellitus. WHO technical report series. No. 727. Geneva, WHO, 1985.

18. Zuidema PJ. Cirrhosis and disseminated calcification of the pancreas in patients with malnutrition. Trop Geogr Med. 1959; 11: 70-74.

19. Kini MG. Multiple pancreatic calculi with chronic pancreatitis. Br J Surg. 1937; 25: 705.

20. Geevarghese PJ. Pancreatic diabetes. Bombay, Popular Prakashan, 1968, pp 110-15.

21. Balakrishnan V, Nair P, Radhakrishnan L, Narayanan VA. Tropical pancreatitis: A distinct entity, or merely a type of chronic pancreatitis? Indian J Gastroenterol. 2006; 25; 74-81.

22. Azad Khan AK, Banik NG, Mahatab H. Malnutrition related diabetes mellitus in Bangladesh. Rifkin H, Colwell JA, Taylor SI (eds). ICS 1000. Amster- dam, Excerpta Medica, 1991, pp 944-49.

23. Trowel HC, Davies JNP, Dean RFA. Kwashiorkor. London, Edward Arnold, 1954, pp 123-48.

24. Amadife MU, Muogbo DC. Chronic calcific pancreatitis presenting with stunting and diabetes mellitus. Niger J Clin Pract. 2008; 11: 254-56.

25. Chowdhury ZM, McDermott MF, Davey S, Hassan Z, Sinnott PJ, Hemmatpour SK, Sherwin S, Ali L, Aganna E, Allotey RA, North BV. Genetic susceptibility to fibrocalculous pancreatic diabetes in Bangladeshi subjects: A family study. Genes Immun. 2002; 3: 5-8.

26. Ralapanawa DM, Jayawickreme KP, Ekanayake EM. Fibrocalculous pancreatic diabetes: A case report. BMC Res Notes. 2015; 8: 1-4.

27. Mohan V, Sadhasivayya J, Nagalotimath S, Yajnik C, Tripathy B. Fibrocalculous pancreatic diabetes. Diabetes Metab Rev. 1998; 14: 153-70.

28. Mohan V, Ramachandran A, Viswanathan M. Two case reports of macrovascular complications in fibrocalculous pancreatic diabetes. Acta Diab Lat. 1989; 26: 345-49.

29. Mohan V, Barman KK, Rajan VS, Chari ST, Deepa R. Natural history of endocrine failure in tropical chronic pancreatitis: A longitudinal follow-up study. J Gastroenterol Hepatol. 2005; 20: 1927-34.

30. Hasan MM, Laila SZ, Mamun MH. Clinical pattern and management of acute pancreatitis: Our experience. J Bangladesh Coll Physicians Surg. 2013; 31: 122-27. 